\title{
Study on Establishing Administrative Approval for Piloting Institutions
}

\author{
Xia Qian ${ }^{1,}{ }^{*}$, Yang Bihan ${ }^{2}$ \\ ${ }^{1}$ School of Arts and Law.Wuhan University of Technology ,China \\ ${ }^{2}$ School of Arts and Law.Wuhan University of Technology ,China \\ *Email:158437327@qq.com
}

\begin{abstract}
Piloting is a kind of unique service based on grasp of local knowledge and special circumstances often occurring within piloting areas. In terms of form, piloting is the behavior of helping ship navigate by staff with professional knowledge, experience and skills in order to ensure safe navigation and avoid accidents. Piloting institutions are legal representatives which provide professional piloting services. This paper mainly argues via data that the establishment of piloting institutions shall be approved by relevant government organs rather than completely by the market. The ideal model is to establish a piloting management mechanism with Chinese characteristics of managing by government departments, self-disciplining by industrial associations and independently operating by piloting institutions so as to adapt to development requirements of Chinese socialist market economy.
\end{abstract}

Key words: piloting institutions, establishment, administrative approval

China's piloting institutions are set up according to regulations in "Notice of Opinions about Implementing China's Port Piloting Management System Reform" (Jiao Shui Fa [2005] No. 483) and the principle of "one port (one water) one pilot". Competent departments in charge of local ports propose an application and submit to Ministry of Transport for approval. It's managed by competent port departments. The water transport division of Ministry of Transport takes responsibility for administrative approval and qualification review of piloting institutions. Without approval of Ministry Transport, the establishment of piloting institutions is illegal.

\section{Implementation Overview and Effect}

According to questionnaire survey data, while analyzing the effect of administrative approval implementation for piloting institutions, staff of shipping enterprises (76.2\%) and seamen (80.6\%) maintain that the greatest effect of administrative approval implementation for piloting institutions is demonstrated in that it increased the safety level of ship entry and exit while staff of the maritime system $(81.6 \%)$ hold that the greatest effect lies in its promotion of standardized management of piloting institutions. Besides, according to shipping enterprises $(62.2 \%)$ and seamen $(58.3 \%)$, it has facilitated healthy development of the piloting industry and the effect is not prominent compared with other effects. staff of the maritime system $(69.1 \%)$ states that the effect in ensuring safety and legal rights and benefits of piloting objects is weak. See Fig. 1 for concrete details.

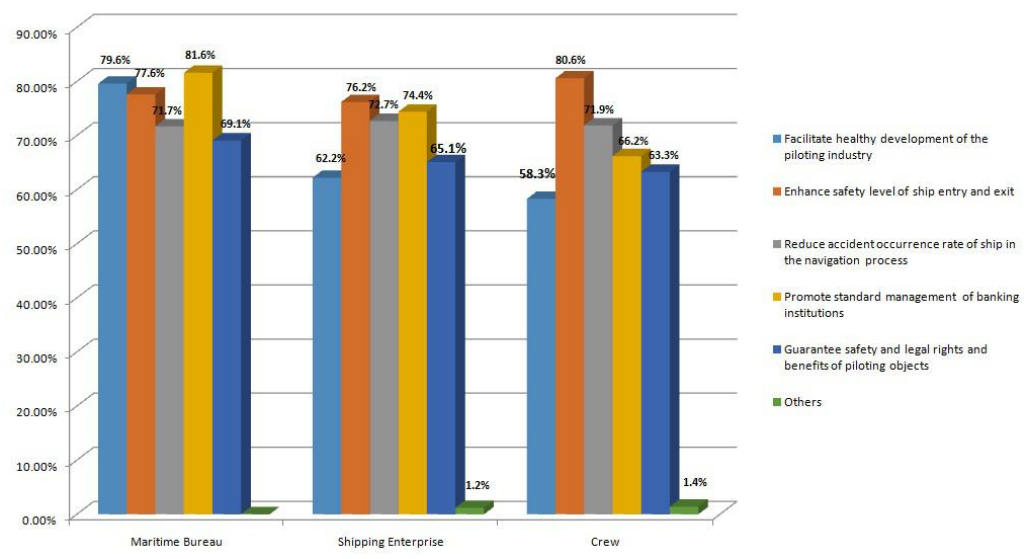

Fig. 1 Effect of Administrative Approval Implementation for Piloting Institutions 


\section{1 Facilitate healthy development of the piloting industry}

According to results of the survey, $79.6 \%$ of management staff in the marine bureau and $62.2 \%$ of shipping enterprises as well as $58.3 \%$ of seamen remarked that implementation of the approval project facilitates healthy development of the piloting industry. The licensing and licensed relation between relevant transport departments and piloting institutions is clarified in both law and practice through the approval project, thus making relevant departments conduct strict and effective supervision and management of piloting institutions, and boosting healthy development of the piloting industry.

\section{2 Enhance safety level of ship entry and exit}

Results of the survey show that $77.6 \%$ of management staff in the marine bureau, $76.2 \%$ shipping enterprises and $80.6 \%$ of seamen stated that implementation of the approval project has enhanced the safety level of ship entry and exit. Seamen are most satisfied with substantial effect brought about by the approval project. "Since implementation of "Marine Safety Law" and "Regulations on Ship Piloting Management", local piloting institutions have regarded piloting safety as the top priority.

\subsection{Reduce accident occurrence rate of ship in the navigation process}

The survey results indicate that $71.7 \%$ of management staff in the marine bureau, $72.7 \%$ shipping enterprises and $71.9 \%$ of seamen hold that implementation of the approval project has reduced accident occurrence rate of ship in the piloting process. Administrative approval for establishment of piloting institutions effectively prevents establishment of unqualified piloting institutions, further reduces and avoids occurrence of marine accidents to the greatest extent, guarantees safety of port ship piloting, avoids and lowers the accident occurrence rate of ship in the piloting process.

\subsection{Promote standard management of banking institutions}

In accordance with survey results, $81.6 \%$ of management staff in the marine bureau, $74.4 \%$ shipping enterprises and $66.2 \%$ of seamen stated that implementation of the approval project has promoted standard management of the piloting organization. Among all factors influencing piloting accidents, pilot factor, other ship factor and natural factor rank top three for all accidents and are main causes for piloting accidents. The artificial pilot factor is the major reason, followed by other ship factor and natural factor. It can be noted that strengthening standard operation plays an obvious role in mitigating piloting accidents, reducing accident risks and establishing a long-term piloting safety mechanism.

\subsection{Guarantee safety and legal rights and benefits of piloting objects}

It can be known from survey results that $69.1 \%$ of management staff in the marine bureau, $65.1 \%$ shipping enterprises and $63.3 \%$ of seamen hold that implementation of the approval project has guaranteed safety and legal rights and benefits of piloting objects. The approval establishment for piloting institutions can make sure that piloting institutions are in line with qualification requirements, and supervise them to shoulder and organize ship piloting tasks within their port and water areas, thus being conducive to ensuring safe navigation and legal rights and benefits of service objects.

\section{Necessity and Rationality Argumentation}

Approval establishment for piloting institutions is necessary and rational for marine safety. Fig. 2 shows opinions of management staff in the marine bureau, management staff in shipping enterprises and seamen about approval establishment for piloting institutions. 


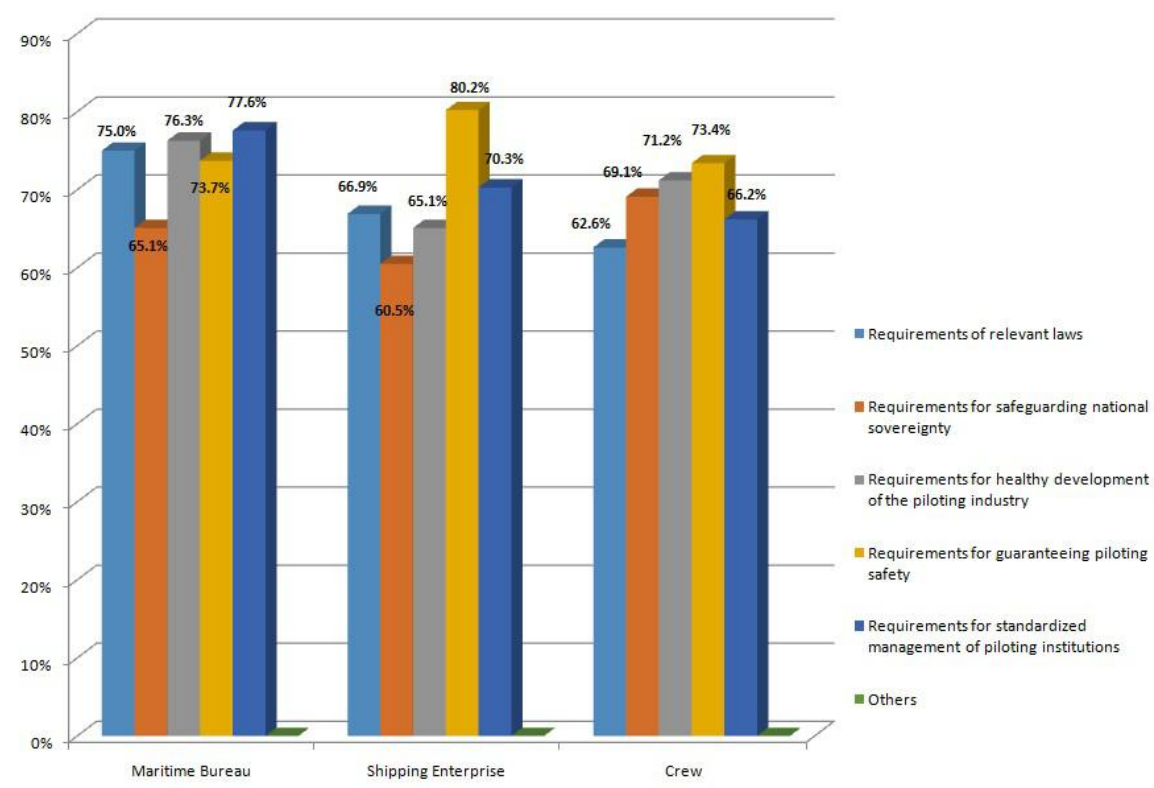

Fig. 2 Necessity and Rationality of Administrative Approval Implementation for Establishment of Piloting Institutions

\subsection{Demand of relevant laws}

According to survey results, $75 \%$ of management staff in the marine bureau, $66.9 \%$ shipping enterprises and $62.6 \%$ of seamen state that implementation of the approval is the requirement of relevant laws. Approval establishment for piloting institutions is explicitly stipulated in laws such as "Administrative Permission Law", "Marine Safety Law" and "Port Law" which must strictly followed as required.

\subsection{Requirements for safeguarding national sovereignty}

Pursuant to survey results, $65.1 \%$ of management staff in the marine bureau, $60.5 \%$ shipping enterprises and $69.1 \%$ of seamen maintain that implementation of the approval is the requirement for safeguarding national sovereignty. Piloting has the property of national sovereignty. A country's piloting area like port route serves as the national "gate" symbol to some extent. Therefore, piloting institutions are needed to guide the ship, especially foreign ship to enter the country through the gate. The piloting work of pilots matters in navigation safety, port, traffic and even national security. The administrative approval right of government transport departments is of great significance to a sovereign state.

\subsection{Requirements for healthy development of the piloting industry}

It can be noted from survey results that $76.3 \%$ of management staff in the marine bureau, $65.1 \%$ shipping enterprises and $71.2 \%$ of seamen think implementation of the approval is the requirement for healthy development of the piloting industry. Development of the piloting industry is restrained by not only economic and scientific technology development level but also by national policy and industrial system. If the operation of piloting institutions falls short of national management, it is bound to be managed by itself, which will lead to disorder in piloting activities.

\subsection{Requirements for guaranteeing piloting safety}

As shown in survey results, $73.7 \%$ of management staff in the marine bureau, $80.2 \%$ shipping enterprises and $73.4 \%$ of seamen state that implementation of the approval is the requirement for guaranteeing piloting safety. Piloting services provided by piloting institutions are the prerequisite for ensuring safety of ship and port facilities and maintaining normal navigation order. Establishment of piloting institution approval can strictly control access and quantity of piloting institutions, ensure favorable qualification of piloting institutions to the greatest extent and facilitate later-stage management and supervision. Meanwhile, it can strengthen responsible subject awareness of piloting institutions, make them serve navigation requirements with high level and efficiency, promote 
enhancement of the entire service in the piloting industry, guarantee entry and exit safety of port ship to the uttermost, avoid and reduce accident occurrence rate in the piloting process.

\subsection{Requirements for standard management of piloting institutions}

As witnessed in survey results that $77.6 \%$ of management staff in the marine bureau, $70.3 \%$ shipping enterprises and $66.2 \%$ of seamen consider that implementation of the approval is the requirement for standard management of piloting institutions. Piloting institutions are social resources which are of public benefit and sovereignty nature. To ensure healthy development of China's port and shipping industry, standard management of piloting institutions is not to be reckoned with. Deepening and refining piloting management system is of vital importance to the entire piloting industry and even China's port and shipping circle.

\section{Acknowledgement}

It is a project supported by " the Fundamental Research Funds for the Central Universities(WUT: 2013-Ib-044)” )

\section{References}

[1] Sun Jian. A Study on Relevant Legal Issues in Ship Piloting [D]. Ocean University of China, 2008.

[2] LiuGaoyang. A Study on Legal Issues in Ship Piloting [D]. Dalian Maritime University, 2012.

[3] LiangXiaojie. Industrial Features and Property Exploration of Piloting [J]. China Ports, Oct. 2014. 